\title{
Gender and age-dependent differences in body composition changes in response to cardiac rehabilitation exercise training in patients after coronary artery bypass grafting
}

\author{
Małgorzata Socha', Krzysztof Wronecki' ${ }^{2}$, Krzysztof A. Sobiech $^{1}$ \\ ${ }^{1}$ Department of Human Biology, Faculty of Physiotherapy, University School of Physical Education, Wroclaw, Poland \\ ${ }^{2}$ Faculty of Physical Education and Physiotherapy, University of Technology, Opole, Poland
}

Socha M, Wronecki K, Sobiech K.A. Gender and age-dependent differences in body composition changes in response to cardiac rehabilitation exercise training in patients after coronary artery bypass grafting. Ann Agric Environ Med. 2017; 24(3): 517-521. doi: 10.5604/12321966.1230731

\begin{abstract}
Cardiac rehabilitation (CR) is the standard procedure in persons after coronary artery bypass grafting (CABG). Its basic aim is to combat coronary heart disease (CHD) risk factors through physical activity and normalization of body mass. Many authors highlight the differences in response to training in CR as dependent on gender, age and occurrence of accompanying disease. The aim of this study is to assess the effectiveness of a three-week early CR in reference to changing body composition parameters in patients over 50 years of age. The study involved a random group of 65 patients (44 men and 21 women) between the ages of 50-76 (average: $62.6 \pm 7.2$ ) years with CHD following CABG. Anthropometric and body composition (bioelectrical impedance method) measurements were taken at the commencement of $C R$ and after the training programme. After $C R$, body mass and body mass index were reduced in men $<65$ and $\geq 65$ years, and in women $<65$ years. A reduction $\%$ body fat and increase $\%$ fat free mass and $\%$ total body water was observed only in patients $<65$. years. Furthermore, in men $<65$ years, an increase in \% body cell mass was observed. In women $\geq 65$ years, no statistically significant changes were observed in body fat indices and body composition features between initial and final study. Patients $\geq 65$ years of age following surgery over a period of hospital cardiac rehabilitation do not experience the same significant improvement in body composition parameters associated with risk of CHD as middle-aged adults. Older women post-cardiac surgery are characterized by a higher disability index in relation to tolerance to physical stress in comparison with men of the same age and persons $<65$ years of age.
\end{abstract}

Key words

coronary heart disease, cardiac rehabilitation, body composition, eldelry

\section{INTRODUCTION}

Cardiovascular disease, including coronary heart disease (CHD), represents the main cause of death in European Union countries, including Poland. Coronary artery bypass graft surgery (CABG), in accordance with cardiovascular associations, is the method of choice in patients with advanced heart disease. In 2005 in Poland, the CABG procedure was performed in $14.3 \%$ of patients with confirmed $\mathrm{CHD}$, and more frequently in men (17.6\%) when compared with women (10.6\%) [1]. Data concerning mortality and morbidity in men and women post- CABG is contradictory. There is evidence that female gender is a risk factor in CABG surgery. A higher hospital mortality rate was observed in women than men. There are reports that gender does not influence revascularization frequency in the heart muscle or the prognosis for patients with stable CHD [2].

CHD pathogenesis is of a complex nature and dependent on many factors. The most commonly mentioned include dyslipidaemia, hypertension, endothelial dysfunction, diabetes and smoking. The majority of these factors indicate

Address for correspondence: Małgorzata Socha, PhD, Department of Human Biology, University School of Physical Education, Al. I. J. Paderewskiego 35, 51-612 Wroclaw, Poland.

E-mail: malgorzata.socha@awf.wroc.pl

Received: 5 March 2013; accepted: 19 May 2014; first published: January 2017 a tendency to occur with disorders in body composition, excess weight and obesity, significantly associated with lack of physical activity $[3,4,5,6]$. Obesity is a known risk factor for cardiovascular disease, but also muscle mass deficiency, the main component of fat free mass (FFM), is an independent risk factor in patients with $\mathrm{CHD}$. A relationship between increased mortality in CHD patients with low FFM index and simultaneously a low level of body fat (BF) has been described.

Cardiac rehabilitation (CR) is the standard medical procedure in persons post CABG. Its basic aim is to combat $\mathrm{CHD}$ risk factors through physical activity and normalization of body mass $[6,7]$. Expanded CR following cardiac arrest or CABG reduces morbidity and hospitalization periods due to cardiovascular reasons. It is suggested that $\mathrm{CR}$ reduces the risk of death within three years by $25 \%$. Patients participating in CR have an improved body composition profile in the context of CHD risk factors in comparison with a control group. The list of mentioned effects of CR concerning changes in body composition includes reduced body mass, body mass index (BMI) and BF, mainly visceral deposits, and increased FFM. Observations included improved muscle strength, increased FFM and reduced BF, particularly in CR programmes with elements of strength training. Improved endothelial function, increased physical capacity, improved lipid profile, reduced insulin levels in fasting CHD patients were also observed. 
Many authors highlight the differences in response to training in CR as dependent on gender, age and occurrence of accompanying disease, and suggest an individual approach in procedures to combat cardiological risk factors in CHD patients $[8,9,10]$. Tests indicate that women participating in CR are older and present a greater load on the circulatory system. Older CHD patients, when compared to younger, present a higher degree of disability, partly based on lower levels of skeletal muscle strength. The reduced secretion of androgens that comes with age may lead to reduced muscle mass and strength and development of abdominal obesity in older persons. The described process, low level of physical activity and disease result in a low FFM level, which leads to reduced motor capabilities in CHD patients more advanced in age. This results in adverse changes in body composition and is also the cause of varied responses to training.

Research into the use of CR in varied patient groups post heart surgery in the context of risk factor reduction associated with body composition is limited. The aim of this work is to assess the effectiveness of a three-week early hospital CR in reference to body composition changes in patients over 50 years of age.

\section{MATERIALS AND METHOD}

Research was conducted on a randomly selected group of 65 patients after CABG between the ages of 50-76 (average: $62.6 \pm 7.2$ ) at the Lower Silesia Centre for Heart Disease MEDINET in Wroclaw, Poland. All patients were diagnosed with CHD. Following surgery, the patients participated in the second stage of three-week early CR. All subjects were treated pharmacologically in accordance with Polish Cardiological Association guidelines. Criteria for exclusion from the study were: lack of patient consent, age below 50 years, and complications following CABG, constituting contraindications for commencement of $\mathrm{CR}$ according to procedure.

Measurements were taken of each subject's height, body mass, waist and hips, which were than used to calculate BMI [body mass ( $\mathrm{kg}) /$ height $\left(\mathrm{m}^{2}\right)$ ] and WHR [waist $(\mathrm{cm}) /$ hips $(\mathrm{cm})$ ]. Assessment of body fat based on the above indices was performed in accordance with criteria recommended by the WHO. Correct weight-height proportions were defined as $\mathrm{BMI}<25.0 \mathrm{~kg} / \mathrm{m}^{2}$. Waist measurement and WHR were used as indicators of abdominal obesity, with values for men $>102 \mathrm{~cm}$ and $\geq 1.00$ and for women $>88 \mathrm{~cm}$ and $\geq 0.85$, respectively. Body composition was estimated using bioelectrical impedance analysis (BIA), using analyzer STA/BIA RJL-Akern 101/S (Italy). Measurements were taken twice, at the beginning of the three-week CR, and upon completion, prior to discharge from hospital. The following body composition components were analyzed: percent of fatty tissue (BF), fat free mass (FFM), total body water (TBW) and cell mass. Comparison of body composition parameters was performed in age groups $<65$ and $\geq 65$ years, in separate groups for men and women.

The rehabilitation programme included morning gymnastics $(15 \mathrm{~min})$, general conditioning gymnastics $(2 \times 30 \mathrm{~min})$, breathing exercises: diaphragmatic, shoulder relaxing, chest expanding $(2 \times 15 \mathrm{~min})$, relaxation training (30 min), cycle training, and additionally walking, massage and Biotron lamp exposure. An individual cycle training programme was determined using information gathered during the stress test. The stress test was conducted on a bicycle ergometer, Ramp stepped protocol 0-300 Watt. Recordings were made of stress test duration (min:s), power released during the test (Watts), energy expenditure (METs), resting and exercise heart rate (beats/min), maximum systolic and diastolic blood pressure $(\mathrm{mmHg})$. Stress test results provided a basis for qualification of subjects to the appropriate model of the second stage of CR. In the majority of patients (82\%) models D and C were applied, and then B. For the remaining, model D and C (9\%) or only D (9\%).

Statistical calculations were made using Statistica Version 9.0 of Statsoft Poland. The data presented in the text and tables of the work are expressed as mean values \pm standard deviation (SD) for continuous variables and as figures and percentages for qualitative variables. The differences between the two samples of independent variables were studied with the U Mann-Whitney test. The significance of differences between mean values for dependent variables (prior to and following rehabilitations) was analyzed with Wilcoxon's non-parametric test. For comparison of more than two independent groups, the Kruskal-Wallis non-parametric test was used. For comparison of differences between qualitative values, a test of the difference between the indices of the structure was used. A value of $\mathrm{p}<0.05$ was considered statistically significant.

\section{RESULTS}

The characteristics of the patient group post CABG who participated in the second stage of CR are presented in Table 1 . In the random group of 65 patients, the majority were men (67.7\%). The average age of the men did not differ significantly in comparison with the women.

Table 1. Baseline characteristics of study participants

\begin{tabular}{lccc}
\hline Characteristic & Total $(\mathrm{n}=65)$ & Male $(\mathrm{n}=44)$ & Female $(\mathrm{n}=21)$ \\
\hline Age (years) & $62.6 \pm 7.2$ & $61.5 \pm 7.4$ & $64.8 \pm 6.4$ \\
\hline$<65$ years & $40(61.5)$ & $29(65.9)$ & $11(52.4)$ \\
\hline$\geq 65$ years & $25(38.5)$ & $15(34.1)$ & $10(47.6)$ \\
\hline Height $(\mathrm{cm})$ & $167.3 \pm 9.7$ & $172.3 \pm 7.3$ & $156.9 \pm 4.3^{*}$ \\
\hline Weight $(\mathrm{kg})$ & $77.8 \pm 12.1$ & $82.3 \pm 10.2$ & $68.4 \pm 10.4^{*}$ \\
\hline Hips circumference $(\mathrm{cm})$ & $106.3 \pm 8.2$ & $105.0 \pm 5.9$ & $109 \pm 11.3$ \\
\hline Waist circumference $(\mathrm{cm})$ & $98.2 \pm 9.4$ & $100.0 \pm 7.7$ & $94.2 \pm 11.4^{*}$ \\
\hline Abdominal obesity ${ }^{\mathrm{a}}$ & $26(40)$ & $11(25.0)$ & $15(71.4)^{*}$ \\
\hline WHR & $0.92 \pm 0.1$ & $0.95 \pm 0.1$ & $0.87 \pm 0.06^{*}$ \\
\hline Abdominal obesity ${ }^{\mathrm{b}}$ & $29(44.6)$ & $13(29.5)$ & $16(76.2)^{*}$ \\
\hline BMI $\left(\mathrm{kg} / \mathrm{m}^{2}\right)$ & $27.7 \pm 3.4$ & $27.7 \pm 2.7$ & $27.8 \pm 4.5$ \\
\hline$\geq 25 \mathrm{~kg} / \mathrm{m}^{2}$ & $50(79.9)$ & $34(77.3)$ & $16(76.2)$ \\
\hline Obese $^{\mathrm{c}}$ & $61(93.8)$ & $41(93.2)$ & $20(95.2)$ \\
\hline Hypertension $^{2}$ & $51(78.5)$ & $35(79.5)$ & $16(76.1)$ \\
\hline Diabetes mellitus $^{2}$ & $19(29.2)$ & $13(29.5)$ & $6(28.6)$ \\
\hline Nicotinism & $6(9.2)$ & $4(9.1)$ & $2(9.5)$ \\
\hline BMl body mass $)$ & & \\
\hline
\end{tabular}

$\mathrm{BMI}$ - body mass index; WHR - waist to hip ratio.

Values are mean \pm SD or numbers (\%).

${ }^{a}$ Abdominal obesity defined as waist circumference values $>102 \mathrm{~cm}$ in males; $>88 \mathrm{~cm}$ in females. ${ }^{\mathrm{b}}$ Abdominal obesity defined as WHR values $\geq 1.00$ for males; $\geq 0.85$ for females.

'Obese defined BIA method as excessof body fat $\%$ for age $50-70$ years ( $>22 \%$ in males; $>30 \%$ in females.

in females. variables; $\mathrm{p}<0.05$. 
Table 2. Baseline results from electrocardiographic stress test

\begin{tabular}{lcccc}
\hline \multirow{2}{*}{ Parameter } & \multicolumn{2}{c}{ Male $(\mathrm{n}=44)$} & \multicolumn{2}{c}{ Female $(\mathrm{n}=21)$} \\
\cline { 2 - 5 } & $<65$ years & $\geq 65$ years & $<65$ years & $\geq 65$ years \\
\hline $\begin{array}{l}\text { Total time of exercise } \\
\text { (min:s) }\end{array}$ & $6.9 \pm 0.9$ & $6.4 \pm 1.2$ & $6.2 \pm 1.1$ & $4.9 \pm 1.6^{*}$ \\
\hline $\begin{array}{l}\text { Maximum strain } \\
\text { (Watts) }\end{array}$ & $104.2 \pm 21.8$ & $91.0 \pm 29.1$ & $88.6 \pm 30.9$ & $61.8 \pm 21.9^{*}$ \\
\hline $\begin{array}{l}\text { Maximum workload } \\
\text { (METs) }\end{array}$ & $4.5 \pm 1.3$ & $4.3 \pm 1.5$ & $4.3 \pm 1.4$ & $3.3 \pm 1.0$ \\
\hline $\begin{array}{l}\text { Baseline heart rate } \\
\text { (beats/min) }\end{array}$ & $78.0 \pm 10.6$ & $71.7 \pm 11.7$ & $70.4 \pm 6.2$ & $75.4 \pm 12.7$ \\
\hline $\begin{array}{l}\text { Peak heart rate } \\
\text { (beats/min) }\end{array}$ & $98.7 \pm 14.3$ & $93.6 \pm 15.5$ & $87.8 \pm 12.2$ & $88.6 \pm 11.7$ \\
\hline $\begin{array}{l}\text { Peak systolic BP } \\
\text { (mmHg) }\end{array}$ & $151.4 \pm 21.3$ & $144.5 \pm 19.8$ & $149.4 \pm 28.3$ & $158.0 \pm 24.9$ \\
\hline $\begin{array}{l}\text { Peak diastolic BP } \\
\text { (mmHg) }\end{array}$ & $80.1 \pm 8.0$ & $76.5 \pm 11.8$ & $81.3 \pm 10.3$ & $85.0 \pm 11.1$ \\
\hline
\end{tabular}

METs - metabolic equivalents; BP - blood pressure

Values are mean \pm SD or numbers (\%).

* Kruskal-Wallis one-way analysis of variance for comparing four age and gender samples, statistically significant difference between males $<65$ years and females $\geq 65$ years; $p<0.05$.

There were also no statistically significant difference between mean BMI values and frequency of accompanying disease. Statistically significant differences in body height ( $\mathrm{p}<0.0001)$, body mass $(\mathrm{p}<0,0001)$, waist measurement $(\mathrm{p}<0.02)$ and WHR $(\mathrm{p}<0,0001)$ were observed in men when compared to women. An increased level of total BF was indicated in $93.8 \%$ of all patients $(93.2 \%$ in men and $95.2 \%$ in women) according to BIA, whereas $76.9 \%$ (77.3\% in men and $76.2 \%$ in women) according to BMI $\left(\geq 25 \mathrm{~kg} / \mathrm{m}^{2}\right)$. The percentage of subjects with excess weight according to both methods did not differ significantly when in comparing the men and women. In $25 \%$ of men, waist measurement exceeded $102 \mathrm{~cm}$, in $71.4 \%$ of women waist measurement exceeded $88 \mathrm{~cm}$. Abdominal obesity, defined with WHR was presented in $76.2 \%$ of women (WHR $\geq 0.85$ ) and $29.5 \%$ of men (WHR $\geq 1$ ). Abdominal obesity, measured as waist measurement and WHR, occurred statistically significantly more frequently in women compared to men $(p<0.04)$. In addition to $\mathrm{CHD}$, the subject patients frequently presented hypertension (78.5\%) and type 2 diabetes (29.2\%) (Tab. 1).

Results of the stress test for men and women in age groups $<65$ and $\geq 65$ are presented in Table 2 . Physical capacity did not differ statistically significantly between the compared groups with consideration of the patients' gender and age, and was accepted as a mean value from $3.3 \pm 1.0$ METs (women $\geq 65$ years) to $4.5 \pm 1.3 \mathrm{METs}$ (men $<65$ years). Among the studied parameters, the only statistically significant difference was in stress test duration (min:s) and power released (Watts) in comparison between men $<65$ and women $\geq 65$ years $(\mathrm{p}<0.05)$. These parameters did not significantly differentiate men in both age groups and women $<65$ years. The average values for resting and exercise heart rate (beats/min) and maximum systolic and diastolic blood pressure $(\mathrm{mmHg})$ were comparable in the subject patient groups with consideration of gender and age.

The effects of the three-week CR exercise programme on anthropometric and BF indices are presented in Table 3. A statistically significant reduction was observed in body mass and BMI in men from both subject age groups $(, \mathrm{p}<0,0005$ and $\mathrm{p}=0.02)$ and in women $<65$ years $(\mathrm{p}=0,005)$. The percentage of observed change in body mass and BMI was greatest in men $<65$ years (respectively, -3.3 and $-3.4 \%$ ), and smallest in men $\geq 65$ years (respectively, $-2.7 \%$ and $-2.9 \%$ ). Changes in body composition according to BIA during CR were observed only in subject patients $<65$ years. BF content in men $<65$ was reduced significantly from an average value of $33.6 \pm 7.1 \%$ at commencement of rehabilitation to $28.7 \pm 7.9 \%$ at completion $(\mathrm{p}=0,003)$, and in women in the same age group from a value of $39.9 \pm 3.3 \%$ to $36.1 \pm 4.5 \%(p=0,006)$. The percentage of observed change in BF levels was far greater in men than in women (respectively, -17.6 and -9.5\%). Only in subject patients $<65$ years did the CR exercise programme

Table 3. Effects of early stage cardiac rehabilitation exercise training on body composition parameters

\begin{tabular}{|c|c|c|c|c|c|c|c|c|}
\hline \multirow{4}{*}{ Parameter } & \multicolumn{8}{|c|}{ Age } \\
\hline & \multicolumn{4}{|c|}{$<65$ years } & \multicolumn{4}{|c|}{$\geq 65$ years } \\
\hline & \multicolumn{2}{|c|}{ Rehabilitation } & \multirow{2}{*}{$\%$ Change } & \multirow{2}{*}{$p$} & \multicolumn{2}{|c|}{ Rehabilitation } & \multirow{2}{*}{$\%$ Change } & \multirow{2}{*}{$\mathrm{p}$} \\
\hline & Baseline & 3 weeks & & & Baseline & 3 weeks & & \\
\hline Male & $n=29$ & & & & $n=15$ & & & \\
\hline Weight (kg) & $83.7 \pm 11.0$ & $80.9 \pm 9.9$ & -3.3 & $0,0004^{*}$ & $79.7 \pm 8.2$ & $77.5 \pm 8.9$ & -2.7 & $0.02 *$ \\
\hline BF (\%) & $33.6 \pm 7.1$ & $28.7 \pm 7.9$ & -17.6 & $0,003^{*}$ & $35.1 \pm 7.3$ & $33.7 \pm 8.4$ & -4.0 & NS \\
\hline FFM (\%) & $66.4 \pm 7.1$ & $71.2 \pm 7.5$ & +7.2 & $0,003^{*}$ & $64.9 \pm 7.3$ & $68.3 \pm 8.4$ & +5.2 & NS \\
\hline TBW (\%) & $50.1 \pm 3.5$ & $53.0 \pm 4.1$ & +5.4 & $0,0004^{*}$ & $49.9 \pm 3.0$ & $51.8 \pm 4.2$ & +3.8 & NS \\
\hline BCM (\%) & $32.9 \pm 4.8$ & $34.9 \pm 4.3$ & +6.1 & $0,0005^{*}$ & $30.1 \pm 3.3$ & $31.1 \pm 4.0$ & +3.3 & NS \\
\hline Female & $n=11$ & & & & $n=10$ & & & \\
\hline BMI & $28.1 \pm 4.7$ & $27.2 \pm 4.5$ & -3.2 & $0,005^{*}$ & $27.6 \pm 4.6$ & $27.2 \pm 4.2$ & -1.4 & NS \\
\hline $\mathrm{BF}(\%)$ & $39.9 \pm 3.3$ & $36.1 \pm 4.5$ & -9.5 & $0,006^{*}$ & $36.9 \pm 3.9$ & $36.3 \pm 4.2$ & -1.6 & NS \\
\hline FFM (\%) & $60.1 \pm 3.3$ & $63.9 \pm 4.5$ & +6.3 & $0,006^{*}$ & $63.2 \pm 3.9$ & $63.7 \pm 4.2$ & +0.8 & NS \\
\hline TBW (\%) & $44.6 \pm 5.1$ & $47.1 \pm 6.1$ & +5.6 & $0,005^{*}$ & $45.5 \pm 4.5$ & $46.1 \pm 4.7$ & +1.3 & NS \\
\hline BCM (\%) & $28.7 \pm 2.0$ & $29.5 \pm 2.4$ & +2.8 & NS & $29.3 \pm 2.4$ & $30.2 \pm 3.0$ & +3.1 & NS \\
\hline
\end{tabular}

BMI - body mass index; BF - body fat; FFM - fat free mass; TBW - total body water; BCM - body cell mass; NS - not statistically significant.

Values are mean $\pm \mathrm{SD}$.

* Comparison at baseline and end of exercise programme; Wilcoxon signed-rank test to compare two dependent variables; $p<0.05$. 
significantly influence an increased proportion of FFM in body composition, in men from an average value of $66.4 \pm$ $7.1 \%$ before to $71.2 \pm 7.5 \%$ after $\mathrm{CR}(\mathrm{p}=0,003)$, and in women, respectively, from $60.1 \pm 3.3 \%$ to $63.9 \pm 4.5 \%(\mathrm{p}=0,006)$. Only in men $<65$ years there was observed a percentage increase of BCM in body composition from a value of $32.9 \pm$ $4.8 \%$ to $34.9 \pm 4.3 \%(\mathrm{p}=0,0005)$. The statistically significant changes in TBW \% observed in patients $<65$ years $(\mathrm{p}=$ 0,0004 in men and $p=0.005$ in women) are a manifestation of reduced BF content and increased muscle mass. In women $\geq 65$ years, no statistically significant changes were observed of mean values of anthropometric characteristics and body composition components according to BIA during the CR exercise programme.

\section{DISCUSSION}

According to the National Institute of Health, CABG is currently the most recommended surgical procedure among CHD patients, which increases chances of survival in comparison with non-surgical procedures. Research shows that more men than women with confirmed CHD undergo the CABG procedure, although the long-term benefits of this treatment method are comparable for both genders [11]. In the presented study, women accounted for $32 \%$ of subject patients from a randomly selected group of patients over the age of 50 who had undergone the CABG procedure.

Among the risk factors for $\mathrm{CHD}$, together with smoking, the most frequently mentioned are body composition disorders resulting from excess $\mathrm{BF}$. It has been shown that a high level of fat measured according to BMI is associated with an increased risk of repeat coronary incidents, particularly among obese patients [3]. In the current research, $77 \%$ of men and $76 \%$ of women had BMI $\geq 25 \mathrm{~kg} / \mathrm{m}^{2}$ and presented increased fat according to BIA - above $22 \%$ in men and above $30 \%$ in women - respectively $93 \%$ and $95 \%$ (Tab. 1). Central fatty tissue distribution has a greater significance in the assessment of CHD risk. From population-based studies of persons over the age of 45 , it is observed that abdominal obesity indicators in both genders are positively associated with CHD, independently of BMI and conventional coronary heart disease risk factors, and are higher in women than in men [4]. Abramov et al. [2] have shown that the difference in risk factor profiles of men and women has a greater influence on treatment outcomes than female gender. Tests on men in middle and advanced age indicated a weak correlation between abdominal fat tissue, measured both in terms of WHR and waist measurement, and CHD risk [12]. In older women, visceral fat tissue is an independent heart disease risk factor [5]. Similarly, in the subject group of patients above the age of 50, abdominal obesity measured in waist measurement and WHR was present statistically significantly more frequently in women (respectively, $71 \%$ and $76 \%$ ) than in men (respectively, 25\% and $29.5 \%$ ). However, no differentiation was observed between the genders concerning the frequency of other accompanying disease (Tab. 1). Hypertension presented in more than $75 \%$ of patients, and almost $30 \%$ suffered from type 2 diabetes.

$\mathrm{CR}$ is a scientifically proven method for reducing mortality, hospitalization and improvement in life quality for all cardiologic patient groups, regardless of age, gender or cardiac pathology [7]. Participation in CR following a heart attack and in post CABG patients is associated with a significant reduction in mortality independently of other treatment methods [13]. The beneficial effects of CR are observed in patients with heart failure, as well as older persons [17] in whom the degree of improvement in organism function following CR is independent of the occurrence of an accompanying disease [14]. Early post-surgery CR significantly improves physical capacity and life quality in post CABG patients [15]. The expected effects of change in body composition under the influence of CR training, in the context of reduced $\mathrm{CHD}$ risk factors, include reduced $\mathrm{BF}$ mass and increased muscle mass. In the subject group of post CABG patients, the benefits of participation in the three-week training programme in terms of change in body composition indicated differentiation depending on gender and age (Tab. $3)$. In the majority of subjects, with the exception of women $\geq 65$ years, there was observed a reduction in body mass and general fat, measured according to BMI. The greatest difference in body mass and BMI between the initial and final examinations were observed in the group $<65$ years, and was comparable for men and women. In the group of men $\geq 65$ years a smaller difference in these characteristics was observed. Changes in the remaining body composition parameters, including fat level, hydration and muscle mass development were observed only in subject patients $<65$ years. No statistically significant changes in body composition were observed in response to training for men and women $\geq 65$ years. Similarly, studies conducted by [16] did not indicate an improvement in body composition parameters resulting from CR in persons $\geq 65$ years. In the group of younger subjects, the rebuilding of body composition took a similar course in both genderss. All of the effects of change in body composition changed significantly between the 1st and 3rd weeks of CR in both groups, although the changes were greater in men than in women. Benefits from participation in $\mathrm{CR}$ training involved reduced $\mathrm{BF}$ and development of muscle mass, the main component of LBM, the result of which was a statistically significant change in body water content. Furthermore, in men $<65$ years participating in rehabilitation gymnastics there was a significant increase in the percentage of BCM, an indicator of muscle mass development. Also, studies of patients with heart failure conducted by [6] show that women at the age of 60 present similar patterns of improvement during CR when compared with men. Hospital CR programmes are particularly valuable for patients of an advanced age, who are not yet ready to be discharged following serious cardiac function disorders [17]. British observations conducted between 1993-2006 indicate that CR participants are increasingly older, which may result in the necessity to introduce changes into existing CR programmes [8]. These observations are confirmed in the presented findings.

A 3-week hospital CR programme provides the greatest benefit in the reduction of cardiological CHD risk factors associated with body composition in men and women post $\mathrm{CABG}$ at an age $<65$ years, whereas in men $\geq 65$ it results only in reduced body mass and BMI. However, it does not induce any statistically significant change in body composition in older women. The creation of new therapeutic strategies within the scope of CR may be of significance with an ageing population, as highlighted by [18].

Studies show that despite the numerous proven benefits of participation in $\mathrm{CR}$, the method remains to a large 
degree unexploited in women [9]. Daniels et al. [10] draws attention to the diversity in heart disease pathophysiology in women in the context of CR. Multi-factor analysis has shown low physical capacity, high BMI, smoking, diabetes and widowhood to be significant independent factors in the premature failure of CR. A low level has been shown of CR application in women post-cardiac surgery and hospitalized for extended periods [20]. Grace et al. [21] showed that, in comparison with men, women are less willing to participate in CR and more frequently consider physical exercise to be tiring and painful. Women are significantly more likely than men to resign from CR due to greater health problems, particularly concerning skeletal muscles, and for other medical reasons [22]. Women have higher BMI, more accompanying diseases, more frequently require immediate surgery, and are older at the time of surgery [23]. Women post $C A B G$ present more serious symptoms of depression, greater symptoms of anxiety and worse rehabilitation results in relation to level of stress after training [24]. During CR, women less frequently participate in training, are older and present a greater burden on the circulatory system, and the rehabilitation programme for them is longer [25]. The findings of the current study also confirm these observation.

No statistically significant differences were found in physical capacity, defined on the basis of a stress test, between the compared groups with consideration of division by patient age and gender. However, the stress test duration and power released during the test were significantly lower in the group of women $\geq 65$ years (Tab. 2). The age and gender dependent differences in physiological effects over the three-week post surgical CR programme may be explained by a greater increase in body composition parameters in patients with a mean age $<65$ years when compared with the older age group, and in men when compared with women. Furthermore, these result from the ageing process which changes body composition and has an influence on the organism's physical capacity.

\section{CONCLUSIONS}

Patients $\geq 65$ years of age following CABG surgery over a period of hospital CR did not experience the same significant improvement in body composition parameters associated with risk of $\mathrm{CHD}$ as middle-aged adults. Older women post CABG are characterized by a higher disability index in relation to tolerance to physical stress in comparison with men of the same age and persons $<65$ years of age.

\section{REFERENCES}

1. Banasiak W, Pociupany R, Wilkins A, Ponikowski P. Characteristics of patients with coronary artery disease managed on an outpatient basis in the population of Poland. Results of the multicentre RECENT trial. Kardiol Pol. 2007; 65: 132-140.

2. Abramov D, Tamariz MG, Sever JY, Christakis GT, Bhatnagar G, Heenan AL et al. The influence of gender on the outcome of coronary artery bypass surgery. Ann Thorac Surg. 2000; 70: 800-805.

3. Rea TD, Heckbert SR, Kaplan RC, Psaty BM, Smith NL, Lemaitre $\mathrm{RN}$ et al. Body mass index and the risk of recurrent coronary events following acute myocardial infarction. Am J Cardiol. 2001; 88(5): $467-472$.
4. Spies C, Farzaneh-Far R, Na B, Kanaya A, Schiller NB, Whooley MA. Relation of obesity to heart failure hospitalization and cardiovascular events in persons with stable coronary heart disease (from the Heart and Soul Study). Am J Cardiol. 2009;104(7): 883-889.

5. Nicklas BJ, Penninx BW, Cesari M, Kritchevsky SB, Newman $A B$, Kanaya AM et al. Association of visceral adipose tissue with incident myocardial infarction in older men and women. The health, aging and body composition study. Am J Epidemiol. 2004; 160(8): 741-749. doi: 10.1093/aje/kwh281

6. Wise FM, Patrick JM. Cardiac rehabilitation outcomes in women with chronic heart failure: mood, fitness, and exercise safety. J Cardiopulm Rehabil Prev. 2012; 32(2): 78-84.

7. Martin BJ, Hauer T, Arena R, Austford LD, Galbraith PD, Lewin AM et al. Cardiac rehabilitation attendance and outcomes in coronary artery disease patients. Circulation. 2012; 126(6): 677-687.

8. Evans J, Bethell H, Turner S, Yadegarfar G. Characteristics of patients entering cardiac rehabilitation in the United Kingdom 1993-2006: implications for the future. J Cardiopulm Rehabil Prev. 2012; 31(3): 181-187.

9. Grace SL, Racco C, Chessex C, Rivera T, Oh P. A narrative review on women and cardiac rehabilitation: program adherence and preferences for alternative models of care. Maturitas. 2010; 67(3): 203-208.

10. Daniels KM, Arena R, Lavie CJ, Forman DE. Cardiac rehabilitation for women across the lifespan. Am J Med. 2012; 125(9): 937.e1-7.

11. Herlitz J, Brandrup-Wognsen G, Karlson BW, Sjoland H, Karlsson $\mathrm{T}$, Caidahl K et al. Mortality, risk indicators of death, mode of death and symptoms of angina pectoris during 5 years after coronary artery bypass grafting in men and women. J Intern Med. 2000; 247: 500-506.

12. Rexrode KM, Buring JE, Manson JE. Abdominal and total adiposity and risk of coronary heart disease in men. Int J Obes Relat Metab Disord. 2001; 25(7): 1047-1056.

13. Dobson LE, Lewin RJ, Doherty P, Batin PD, Megarry S, Gale CP. Is cardiac rehabilitation still relevant in the new millennium? J Cardiovasc Med (Hagerstown). 2012; 13(1): 32-37.

14. Listerman J, Bittner V, Sanderson BK, Brown TM. Cardiac rehabilitation outcomes: impact of comorbidities and age. J Cardiopulm Rehabil Prev. 2011; 31(6): 342-348.

15. Hsu CJ, Chen SY, Su S, Yang MC, Lan C, Chou NK et al. The effect of early cardiac rehabilitation on health-related quality of life among heart transplant recipients and patients with coronary artery bypass graft surgery. Transplant Proc. 2012; 43(7): 2714-2717.

16. Oerkild B, Frederiksen M, Hansen JF, Simonsen L, Skovgaard LT, Prescott E. Home-based cardiac rehabilitation is as effective as centrebased cardiac rehabilitation among elderly with coronary heart disease: results from a randomised clinical trial. Age Ageing. 2012; 40(1): 78-85.

17. Frengley JD, Sansone GR, Alba A, Uppal K, Kleinfeld J. Influence of age on rehabilitation outcomes and survival in post-acute inpatient cardiac rehabilitation. J Cardiopulm Rehabil Prev. 2011; 31(4): 230-238.

18. Hausenloy DJ, Boston-Griffiths E, Yellon DM. Cardioprotection during cardiac burgery. Cardiovasc Res. 2012; doi: 10.1093/cvr/cvs131. Epub 2012 Mar 22

19. Wittmer M, Volpatti M, Piazzalonga S, Hoffmann A. Expectation, satisfaction, and predictors of dropout in cardiac rehabilitation. Eur J Prev Kardiol. 2012; 19(5): 1082-1088.

20. Jegier B, Pietka I, Wojtczak-Soska K, Jaszewski R, Lelonek M. Cardiac rehabilitation after cardiac surgery is limited by gender and length of hospitalisation. Kardiol Pol. 2011; 69(1): 42-46.

21. Grace SL, Gravely-Witte S, Kayaniyil S, Brual J, Suskin N, Stewart DE. A multisite examination of sex differences in cardiac rehabilitation barriers by participation status. J Womens Health (Larchmt). 2009; 18(2): 209-216.

22. Sarrafzadegan N, Rabiei K, Shirani S, Kabir A, Mohammadifard N, Roohafza H. Drop-out predictors in cardiac rehabilitation programmes and the impact of sex differences among coronary heart disease patients in an Iranian sample: a cohort study. Clin Rehabil. 2007; 21(4): 362-372.

23. Czech B, Kucewicz-Czech E, Pacholewicz J, Wojarski J, Puzio J, Przybylski R et al. Early results of coronary artery bypass graft surgery in women. Kardiol Pol. 2007; 65:627-633.

24. Szczepanska-Gieracha J, Morka J, Kowalska J, Kustrzycki W, Rymaszewska. The role of depressive and anxiety symptoms in the evaluation of cardiac rehabilitation efficacy after coronary artery bypass grafting surgery. Eur J Cardiothorac Surg. 2012; 42(5): e108-114.

25. De Feo S, Tramarin R, Ambrosetti M, Riccio C, Temporelli PL, Favretto $\mathrm{G}$ et al. Gender differences in cardiac rehabilitation programs from the Italian survey on cardiac rehabilitation (ISYDE-2008). Int J Cardiol. 2012; 160(2): 133-139. 